\title{
Torta de mamona destoxificada para alimentação de poedeiras comerciais
}

\author{
Detoxified castor cake feed for laying hens
}

\author{
Camila Ferreira Delfim Bueno ${ }^{I}$ Álvaro Luís de Carvalho Veloso ${ }^{I}$ \\ Daniel Emygdio de Faria Filho ${ }^{I I}$ Adélio Nunes Dias ${ }^{I}$ Vanilza Fernandes $^{\mathrm{I}}$

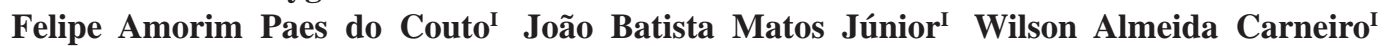

\section{RESUMO}

Objetivou-se com este experimento avaliar o efeito da inclusão de torta de mamona destoxificada (TMD) na ração de poedeiras comerciais sobre o desempenho e a qualidade interna e externa dos ovos. Foram utilizadas 200 poedeiras comerciais de 40 a 50 semanas de idade, da linhagem Hy-Line W-36 ${ }^{\circledR}$, com $1543 \pm 34 \mathrm{~g}$ de peso corporal, que foram distribuídas em um delineamento inteiramente casualizado com cinco tratamentos $(0$, 5, 10, 15 e 20\% de torta de mamona destoxificada na ração) com cinco repetições de oito aves cada. Foram avaliados o consumo de ração, a produção, o peso e a massa de ovos e a conversão alimentar. A qualidade interna foi avaliada por meio da unidade de Haugh, percentual de albúmen e de gema. A qualidade da casca foi medida pela espessura, densidade específica e percentual de casca. As variáveis de desempenho foram afetadas pela inclusão da TMD com resposta linear negativa para o consumo de ração e quadrática para produção de ovos, peso do ovo, massa do ovo e conversão alimentar, com os melhores níveis de 10,5, 5,7, 9,2 e $10,3 \%$ respectivamente. Não houve efeito significativo da inclusão da TMD para as variáveis de qualidade interna e externa dos ovos. Concluiu-se que a TMD pode ser incluída na ração de poedeiras em até 5,7\% para otimizar o desempenho e não alterar a qualidade interna e externa dos ovos.

Palavras-chave: alimento alternativo, ricinina, ricina, Ricinus communis $L$.

\section{ABSTRACT}

This experiment aimed to evaluate the use of detoxified castor cake (DCC) in the diet of laying hens on performance and internal and external quality of eggs. A total of 200 laying hens with 40-50 weeks of age, of Hy-Line W-36 ${ }^{\circledR}$ line, with $1543 \pm 34 \mathrm{~g}$ body weight, were distributed in a completely randomized design with five treatments $(0,5,10,15$ and $20 \%$ of DCC in diet) with five replicates of eight birds each. The feed intake, egg production, egg weight, egg mass and feed conversion were evaluated. The egg internal quality was evaluated by Haugh unit, percentage of albumen and yolk. The shell quality was evaluated by the thickness, density and specific percentage of eggshell. The performance variables were affected by the inclusion of DCC with a negative linear response to food intake and quadratic for egg production, egg weight, egg mass and feed conversion, with the best levels of 10.5, 5.7, 9.2 and 10.3\% respectively. There was no significant effect of DCC inclusion for the variables of egg quality. It is conclude that the DCC can be included in hens diets up to $5.7 \%$ to optimize performance and do not alter the internal and external quality of the eggs.

Key words: alternative feedstuff, ricin, ricinine, Ricinus communis $L$.

\section{INTRODUÇÃO}

Foi lançado no Brasil o Programa Nacional de Produção e Uso de Biodiesel, com o objetivo de implementar de forma sustentável, técnica e econômica a produção e o uso do biodiesel, visando à inclusão social e ao desenvolvimento regional, via geração de emprego e renda (MME, 2005). A mamona é uma oleaginosa com grande potencial de produção do biodiesel, sendo que o óleo da mamona é extraído e utilizado na produção do biodiesel e seu resíduo, o farelo ou a torta da mamona, tem grande potencial nutritivo para utilização na alimentação de frangos de corte e poedeiras comercias, em função do seu teor nutritivo. De acordo com ROSTAGNO et al. (2011), o farelo de mamona tem, em média, na matéria natural, 39,2\% de proteína bruta, 1,55\% de extrato etéreo, $18,5 \%$ de fibra bruta, $0,62 \%$ de cálcio, 0,20\% de fósforo disponível, $0,01 \%$ de sódio, $0,78 \%$ de lisina, $0,61 \%$ de metionina, 0,58\% de triptofano,

'Instituto de Ciências Agrárias (ICA), Universidade Federal de Minas Gerais (UFMG), Montes Claros, MG, Brasil.

${ }^{\text {IF}}$ Faculdade de Zootecnia e Engenharia de Alimentos (FZEA), Universidade de São Paulo (USP), Pirassununga, SP, Brasil. E-mail: fariafilho@usp.br. Autor para correspondência. 
$1,13 \%$ de treonina, $3,21 \%$ de arginina, $1,78 \%$ de valina, 1,75\% de isoleucina, 2,68\% de leucina, 1,35\% de fenilalanina e 1484 kcal de energia metabolizável por kg de farelo de mamona para aves.

A torta de mamona é obtida pela extração mecânica do óleo, apresenta 13\% de óleo (COSTA et al., 2004) e corresponde a aproximadamente 55\% do peso da semente (AZEVEDO \& LIMA, 2001), gerando um rendimento de $550 \mathrm{~kg}$ de torta para cada tonelada de semente processada. PAULINO et al. (2006) estimaram que, entre 2008 e 2013, serão produzidas 240 mil toneladas de farelos e tortas de mamona.

A torta de mamona apresenta substâncias nocivas como a ricina, a ricinina e complexos alergênicos, portanto, precisa ser destoxificada antes da utilização na alimentação animal. OLIVEIRA et al. (2006) testaram diferentes métodos de destoxificação e encontraram a remoção total da ricina da torta de mamona, utilizando $60 \mathrm{~g}$ de óxido de cálcio diluídos em 10 partes de água para cada kg de torta de mamona.

Para a sua utilização de forma segura na alimentação de aves, além da destoxificação (OLIVEIRA et al., 2006), é necessário o conhecimento dos níveis nutricionais, dos teores de energia metabolizável e de digestibilidade dos seus nutrientes (MATOS JÚNIOR et al., 2011; ROSTAGNO et al., 2011). Além disso, são importantes estudos de desempenho, no entanto, não foram encontrados trabalhos na literatura testando os efeitos da inclusão da torta de mamona destoxificada na alimentação de poedeiras comerciais.

Objetivou-se com esse experimento avaliar o efeito da inclusão de torta de mamona destoxificada na ração sobre o desempenho e a qualidade interna e externa dos ovos de poedeiras comerciais.

\section{MATERIAL E MÉTODOS}

Foram utilizadas 200 poedeiras comerciais de 40 a 50 semanas de idade, da linhagem Hy-Line $\mathrm{W}-36^{\circledR}$, com $1543 \pm 34 \mathrm{~g}$ de peso corporal, que foram distribuídas em um delineamento inteiramente casualizado com cinco tratamentos e cinco repetições de oito aves cada. Os tratamentos consistiram na inclusão de torta de mamona destoxificada (TMD) na ração, nos níveis de 0, 5, 10, 15 e 20\%, como apresentado na tabela 1 . As aves foram criadas em gaiolas de arame galvanizado, sob galpão com telha de barro. Empregaram-se 17 horas de luz por dia e espaço de $400 \mathrm{~cm}^{2}$ de área de piso por ave. A ração e a água foram fornecidos à vontade e as aves foram manejadas convencionalmente.

A torta de mamona foi obtida de indústria processadora de mamona da região de Montes Claros - MG. Foi feita destoxificação, de acordo com
OLIVEIRA et al. (2006), utilizando 60g de óxido de cálcio microprocessado para cada kg de torta de mamona. Antes da mistura com a torta de mamona, o óxido de cálcio foi diluído em 10 partes de água. Após 8 horas, a torta de mamona foi colocada para secar em temperatura ambiente. De acordo com OLIVEIRA et al. (2006), essa técnica elimina completamente a ricina por desnaturação das proteínas desta molécula, que é o principal agente tóxico da mamona. A composição nutricional da torta de mamona antes da destoxificação e destoxificada foi determinada conforme SILVA \& QUEIROZ (2002) e encontramse na tabela 2 .

O desempenho foi avaliado por meio do consumo de ração (g/ave/dia), produção de ovos (\% $\mathrm{ave}^{-1} \mathrm{dia}^{-1}$ ), peso dos ovos (g), massa de ovos (g ave $\left.\mathrm{dia}^{-1}\right)$ e conversão alimentar $\left(\mathrm{g} \mathrm{g}^{-1}\right)$.

A qualidade interna e da casca dos ovos foi avaliada em quatro ovos por parcela, as 50 semanas de idade. A qualidade interna dos ovos foi determinada por meio da unidade de Haugh (UH), porcentagens de gema e de albúmen. A UH foi obtida pela fórmula proposta por NESHEIM et al. (1979): UH=100xlog $\left(\mathrm{h}+7,57-1,7 \mathrm{p}^{0,37}\right)$, em que $\mathrm{h}$ refere-se à altura do albúmen (mm) e p representa o peso do ovo (g). A altura do albúmen foi obtida a $1 \mathrm{~cm}$ da gema com auxílio de um altímetro, com divisão de $0,1 \mathrm{~mm}$. O peso dos ovos foi obtido com balança semi-analítica, com divisão de 0,01g. A gema e o albúmen foram obtidos por separação manual e foram pesados em balança semi-analítica, com divisão de 0,01g. A gema e o albúmen foram expressos como percentual do ovo fresco. A qualidade da casca dos ovos foi avaliada por meio da espessura da casca (mm), da porcentagem de casca (\% do ovo fresco) e pela gravidade específica dos ovos (g mL ${ }^{-1}$ água). Para determinação da espessura das cascas, essas foram removidas manualmente, lavadas e colocadas para secar em temperatura ambiente por 72 horas. O percentual de casca foi calculado pela fórmula: 100 - (\% albúmen + \% gema). A espessura da casca foi obtida com medidor de espessura com divisão de $0,01 \mathrm{~mm}$. A gravidade específica foi obtida pela inserção dos ovos em baldes de 20 litros, com gravidades específicas variando de 1,0650 a $1,0950 \mathrm{~g} \mathrm{~mL}^{-1}$, com intervalos de 0,0025 cada, seguindo o protocolo descrito por MORENG \& AVENS (1990).

Os dados foram verificados quanto à presença de dados discrepantes e, em seguida, foram submetidos à análise de normalidade dos erros estudentizados (teste de Cramer-Von-Mises) e de homogeneidade de variâncias (teste de BrownForsythe). Após o atendimento dessas pressuposições, os dados foram submetidos à análise de variância por meio do procedimento General Linear Model do 
Tabela 1 - Rações experimentais para poedeiras comerciais.

\begin{tabular}{|c|c|c|c|c|c|}
\hline \multirow{2}{*}{ Ingredientes } & \multicolumn{5}{|c|}{ - } \\
\hline & 0 & 5 & 10 & 15 & 20 \\
\hline Milho & 63,51 & 59,89 & 56,28 & 52,66 & 49,05 \\
\hline Farelo de soja & 22,07 & 20,46 & 18,85 & 17,23 & 15,62 \\
\hline Torta de mamona destoxificada* & 0,00 & 5,00 & 10,00 & 15,00 & 20,00 \\
\hline Óleo de soja & 1,94 & 2,71 & 3,47 & 4,24 & 5,00 \\
\hline DL-metionina & 0,16 & 0,14 & 0,12 & 0,10 & 0,08 \\
\hline Fosfato bicálcico & 1,78 & 1,76 & 1,74 & 1,72 & 1,70 \\
\hline Calcário calcítico & 9,74 & 9,25 & 8,76 & 8,27 & 7,78 \\
\hline Sal comum & 0,39 & 0,38 & 0,38 & 0,37 & 0,37 \\
\hline Premix** & 0,40 & 0,40 & 0,40 & 0,40 & 0,40 \\
\hline Total & 100,00 & 100,00 & 100,00 & 100,00 & 100,00 \\
\hline Energia e nutrientes & - & -------- & res calcu & י-נ--ני-" & \\
\hline Energia metabolizável $\left(\mathrm{kcal} \mathrm{kg}^{-1}\right)$ & 2816 & 2816 & 2816 & 2816 & 2816 \\
\hline Proteína bruta (\%) & 15,25 & 15,25 & 15,25 & 15,25 & 15,25 \\
\hline Metionina+cistina (\%) & 0,67 & 0,67 & 0,67 & 0,67 & 0,67 \\
\hline Fósforo disponível (\%) & 0,42 & 0,42 & 0,42 & 0,42 & 0,42 \\
\hline Cálcio (\%) & 4,25 & 4,25 & 4,25 & 4,25 & 4,25 \\
\hline Sódio (\%) & 0,17 & 0,17 & 0,17 & 0,17 & 0,17 \\
\hline Fibra bruta (\%) & 2,29 & 3,79 & 5,28 & 6,78 & 8,27 \\
\hline
\end{tabular}

* Composição nutricional apresentada na tabela 2. ** Níveis de garantia por kg do produto: vitamina A 167000UI; vitamina D 335000UI; vitamina E 2500mg; vitamina K 417mg; vitamina B1 250mg; vitamina B2 835mg; vitamina B6 250mg; vitamina B12 2000mcg; ácido fólico 100mg; biotina 9mg; niacina 5835mg; ácido pantotênico 1870mg; colina 116670mg; cobre 1000mg; iodo 170mg; ferro 8335mg; manganês 10835mg, zinco 7500mg; selênio 35mg; antioxidante 2000mg; veículo qsp 1000g.

programa SAS ${ }^{\circledR}$ (LITTELL et al., 2002) e, em caso de significância, ajustou-se regressão polinomial (FREUND \& LITTELL, 2000).

\section{RESULTADOS E DISCUSSÃO}

Houve resposta linear negativa para o consumo de ração (Tabela 3), quando se encontrou que, para cada ponto percentual de inclusão de TMD, ocorre redução de 0,549 g no consumo de ração. À medida que se incluiu a TMD, ocorreu aumento do teor de fibra bruta da ração, como pode ser constatado na tabela 1. A diminuição do consumo de ração pode ser explicada pelo aumento do teor de fibra bruta, que aumenta a sensação de saciedade (BERTECHINI, 2006). Também, segundo ANI \& OKORIE (2008), a mamona apresenta baixa palatabilidade e um fator depressor de apetite que podem ter contribuído para

Tabela 2 - Composição nutricional (na matéria natural) da torta de mamona.

\begin{tabular}{lcc}
\hline & & \\
Nutriente* & Antes da destoxificação & Destoxificada \\
\hline Matéria seca (\%) & 91,5 & 91,8 \\
Proteína bruta (\%) & 20,1 & 20,6 \\
Extrato etéreo (\%) & 24,2 & 18,2 \\
Fibra bruta (\%) & 34,6 & 32,9 \\
Extrativo não nitrogenado (\%) & 6,3 & 9,1 \\
Matéria Mineral (\%) & 6,3 & 11,0 \\
Cálcio (\%) & 0,58 & 3,97 \\
Fósforo (\%) & 0,49 & 0,57 \\
Sódio (\%) & 0,05 & 0,05 \\
Energia metabolizável $\left(\mathrm{kcal} \mathrm{kg}^{-1}\right)$ & - & 1829 \\
\hline
\end{tabular}

* Valores analisados, exceto energia metabolizável, de acordo com MATOS JÚNIOR et al. (2011).

Ciência Rural, v.44, n.3, mar, 2014. 
Tabela 3 - Consumo de ração (CR; g ave ${ }^{-1}$ dia $^{-1}$ ), produção de ovos (PR; \% ave ${ }^{-1}$ dia $^{-1}$ ), peso do ovo (PO; g ave ${ }^{-1}$ dia $\left.{ }^{-1}\right)$, massa dos ovos (MO; $\mathrm{g} \mathrm{ave}^{-1} \mathrm{dia}^{-1}$ ) e conversão alimentar (CA; $\mathrm{g} \mathrm{g}^{-1}$ ) de poedeiras comerciais alimentadas com torta de mamona destoxificada.

\begin{tabular}{|c|c|c|c|c|c|}
\hline Torta de mamona destoxificada (\%) & CR & PR & $\mathrm{PO}$ & MO & CA \\
\hline 0 & 115,16 & 72,65 & 67,69 & 49,11 & 2,345 \\
\hline 5 & 112,68 & 76,34 & 67,82 & 51,81 & 2,175 \\
\hline 10 & 113,15 & 80,96 & 67,79 & 54,85 & 2,063 \\
\hline 15 & 107,27 & 77,00 & 67,03 & 50,15 & 2,139 \\
\hline 20 & 104,13 & 74,02 & 65,53 & 48,07 & 2,166 \\
\hline Análise de variância & $* *$ & $*$ & $*$ & $*$ & $*$ \\
\hline \multicolumn{6}{|l|}{ Análise de regressão } \\
\hline Intercepto & $115,9 * *$ & $72,4 * *$ & $67,62 * *$ & $49,08 * *$ & $2,34 * *$ \\
\hline Linear & $-0,549 * *$ & $1,321^{*}$ & $0,126^{*}$ & $0,913^{*}$ & $-0,041^{*}$ \\
\hline Quadrática & NS & $-0,063^{*}$ & $-0,011^{*}$ & $-0,049 *$ & $0,002 * *$ \\
\hline $\mathrm{R}^{2}$ & 0,89 & 0,87 & 0,99 & 0,80 & 0,93 \\
\hline CV (\%) & 5,49 & 6,33 & 3,75 & 5,91 & 3,12 \\
\hline
\end{tabular}

TMD = torta de mamona destoxificada. $\mathrm{R}^{2}=$ coeficiente de determinação. $\mathrm{CV}=$ coeficiente de variação. ${ }^{\mathrm{NS}} \mathrm{P}>0,05 .{ }^{*} \mathrm{P}<0,05 . * *$ P<0,01.

diminuir o consumo de ração. Os resultados da presente pesquisa concordam com os obtidos por SANTOS (2011), o qual incluiu farelo de mamona destoxificado na ração de codornas japonesas, nos níveis de $0,5,10,15$ e 20\%, e encontrou que a inclusão do farelo de mamona em qualquer nível reduz o consumo de ração em relação ao tratamento com $0 \%$ de desse alimento.

A produção de ovos, peso do ovo, massa do ovo e conversão alimentar (Tabela 3) foram influenciadas de forma quadrática pela inclusão da TMD e os níveis ótimos de inclusão foram 10,5, 5,7, 9,2 e 10,3\%, respectivamente. Mesmo com redução linear do consumo de ração, ocorreu melhora nos índices de desempenho das aves até os níveis ótimos de inclusão de TMD referidos anteriormente, o que pode ser explicado pelo aumento do óleo de soja na composição da ração (Tabela 1 ). O alto teor de gordura estimula o hormônio colecistocinina, que estimula a produção de lipase, protease e amilase (BERTECHINI, 2006), assim como o alto teor de gordura diminui a taxa de passagem do alimento (ANDREOTTI et al., 2004), expondo-o a uma atividade enzimática maior no trato digestório (BERTECHINI, 2006). Dessa forma, a menor taxa de passagem do alimento junto com maior produção de enzimas provavelmente permitiu maior absorção de seus nutrientes, o que justifica o melhor desempenho quando se inclui de 5,7 a 10,3\% de TMD. A queda do desempenho a partir daqueles níveis ótimos de inclusão de TMD na ração é, provavelmente, devido à redução do consumo de ração para níveis críticos, em que as exigências nutricionais das aves não foram supridas. Por exemplo, considerando o consumo de ração das aves (Tabela 3) e o teor de proteína bruta das rações de 15,25\% (Tabela 1), constata-se que o consumo de proteína bruta pelas poedeiras foi de 17,$56 ; 17,18 ; 17,25 ; 16,35$ e $15,88 \mathrm{~g}$ por dia para as inclusões de 0, 5, 10, 15 e 20\% de TMD na ração, respectivamente. ROSTAGNO et al. (2011) recomenda, para poedeiras leves, $16,5 \mathrm{~g}$ de proteína por dia, dessa forma, os tratamentos com 15 e $20 \%$ de inclusão de TMD não proporcionaram consumo de proteína suficiente para suprir a exigência deste nutriente. Outro fator que pode ter contribuído para o menor desempenho das aves alimentadas com alto nível de inclusão de TMD é o alto teor de fibra bruta das dietas, que pode ter diminuído o aproveitamento da energia e dos nutrientes, pois a fibra constitui um impedimento físico ao acesso das enzimas do trato digestório aos nutrientes. De acordo com dados apresentados por BERTECHINI (2006), dietas com elevado teor de fibra bruta na ração diminuem a digestibilidade do extrativo não nitrogenado para aves. Os resultados da presente pesquisa concordam parcialmente com os obtidos por SANTOS (2011), que encontrou redução significativa na produção de ovos e massa dos ovos de codornas japonesas, quando incluiu 15 e 20\% de farelo de mamona destoxificado em relação à ração com $0 \%$ de inclusão de mamona. No entanto, a conversão alimentar só piorou quando se incluiu $20 \%$ de farelo de mamona em relação ao tratamento sem inclusão (SANTOS, 2011). Da mesma maneira, os resultados da presente pesquisa corroboram parcialmente os obtidos por ANI \& OKORIE (2004; 2005 e 2008), que trabalharam com frangos de corte e verificaram ser possível a inclusão de até $10 \%$ de mamona destoxificada na fase inicial e final da criação sem prejudicar o desempenho.

Não houve efeito significativo para qualidade da casca e qualidade interna do ovo (Tabela 4) em função dos diferentes níveis de inclusão de TMD na 
Tabela 4 - Gravidade específica (GE, g mL ${ }^{-1}$ ), percentagem de casca (Casca; \%), espessura da casca (ESP; mm), percentagem de albúmen (Albúmen; \%), percentagem de gema (Gema; \%) e unidade de Haugh (UH) de poedeiras comerciais alimentadas com torta de mamona destoxificada.

\begin{tabular}{llccccc}
\hline Torta de mamona destoxificada (\%) & GE & Casca & ESP & Albúmen & Gema & UH \\
\hline 0 & 1,082 & 15,3 & 0,573 & 59,7 & 24,9 & 91,7 \\
5 & 1,081 & 14,9 & 0,574 & 59,6 & 25,5 & 92,3 \\
10 & 1,083 & 15,0 & 0,576 & 59,8 & 25,3 & 94,1 \\
15 & 1,085 & 15,2 & 0,581 & 60,2 & 24,6 & 94,8 \\
20 & 1,084 & 15,6 & 0,577 & 58,8 & 25,6 & 91,8 \\
Análise de variância & NS & NS & NS & Ns & Ns & Ns \\
CV (\%) & 0,96 & 5,97 & 2,38 & 4,31 & 2,39 & 2,72 \\
\hline
\end{tabular}

$\mathrm{TMD}=$ torta de mamona destoxificada. $\mathrm{R}^{2}=$ coeficiente de determinação. $\mathrm{CV}=$ coeficiente de variação. ${ }^{\mathrm{NS}} \mathrm{P}>0,05$.

alimentação das poedeiras, indicando ser possível a inclusão de até $20 \%$ deste alimento sem afetar as variáveis. Os resultados de SANTOS (2011) foram semelhantes aos obtidos neste estudo ao não encontrarem diferença na unidade de Haugh, gravidade específica, espessura da casca e no peso e percentual da gema e do albúmen entre os tratamentos com farelo de mamona destoxificados para codornas japonesas (5, 10, 15 e 20\% de inclusão) e a dieta com 0\% de inclusão. No entanto, SANTOS (2011) encontraram menor percentual de casca e menor peso da casca para codornas japonesas alimentadas com 10 e $20 \%$ de farelo de mamona destoxificados, respectivamente, em relação ao tratamento sem inclusão deste alimento. Os autores associaram esses resultados com o menor consumo de ração e consequentemente o menor consumo de cálcio das codornas. Essa piora na qualidade da casca não ocorreu na presente pesquisa.

\section{CONCLUSÃO}

A torta de mamona destoxificada pode ser incluída na ração de poedeiras em até 5,7\% para otimizar o desempenho e não alterar a qualidade interna e externa dos ovos.

\section{COMITÊ DE ÉTICA E BIOSSEGURANÇA}

Os procedimentos experimentais adotados nesta pesquisa foram aprovados pelo Comitê de Ética em Experimentação Animal da Universidade Federal de Minas Gerais, sob protocolo n ${ }^{\circ}$ $59 / 2008$.

\section{REFERÊNCIAS}

ANDREOTTI, M.O. et al. Tempo de trânsito intestinal, desempenho, característica de carcaça e composição corporal de frangos de corte alimentados com rações isoenergéticas formuladas com diferentes níveis de óleo de soja. Revista Brasileira de
Zootecnia, v.33, p.870-879, 2004. Disponível em: <http://www. scielo.br/scielo>. Acesso em: 28 ago. 2012. doi: 10.1590/S151635982004000400007

ANI, A.O.; OKORIE, A.U. The effect of dietary castor oil bean (Ricinus communis L) meal and supplementary L-Lysine on the performance of broiler starter chicks. Discovery and Innovation, v.16, p.46-52, 2004

ANI, A.O.; OKORIE, A.U. The effect of dehulled and cooked castor oil bean (Ricinus communis L) meal on performance of broiler starters. Nigerian Journal of Animal Production, v.16 p.54-60, 2005.

ANI, A.O.; OKORIE, A.U. Response of broiler finishers to diets containing graded levels of processed castor oil bean (Ricinus communis L) meal. Journal of Animal Physiology and Animal Nutrition, v.93, p.157-164, 2008. Disponível em: <http:// onlinelibrary.wiley.com/doi/10.1111/j.1439-0396.2007.00796.x/ abstract;jsessionid=4566BFA1C5FE6A6F8415D3C20CD1D 57A.d01t04>. Acesso em: 28 ago. 2012. doi: 10.1111/j.14390396.2007.00796.x.

AZEVEDO, D.M.P.; LIMA, E.F. (Ed.). 0 agronegócio da mamona no Brasil. Brasília: Embrapa Informação Tecnológica, 2001. 350p.

BERTECHINI, A.G. Nutrição de monogástricos. Lavras: UFLA, 2006. 301p.

COSTA, F.X. et al. Composição química da torta de mamona. In: CONGRESSO BRASILEIRO DE MAMONA, 2004, Campina Grande. Anais... Campina Grande: Empresa Brasileira de Pesquisa Agropecuária, 2004. Disponível em: <http://www.cnpsa. embrapa.br>. Acesso em: 25 de março de 2011.

FREUND, R.J.; LITTELL, R.C. SAS ${ }^{\circledR}$ System for Regression. SAS Institute. 4.ed. Cary, 2000. 235p.

LITTELL, R.C. et al. SAS For Linear Models. SAS Institute. 4.ed. Cary, 2002. 466p.

MATOS JÚNIOR, J. et al. Metabolizable energy and nutrient digestibility of detoxified castor meal and castor cake for poultry. Revista Brasileira de Zootecnia, v.40, n.11, p.2439-2442, 2011. Disponível em: <http://www.scielo.br/scielo.php?pid=S1516- 
35982011001100022\&script=sci_arttext $>$. Acesso em: 28 ago. 2012. doi: 10.1590/S1516-35982011001100022.

MME (MINISTÉRIO DE MINAS E ENERGIA). 2005. Disponível em: <2005.www.mme.gov.br>. Acesso em: 10 fev. 2009.

MORENG, R.E.; AVENS, J.S. Ciência e produção de aves. São Paulo: Roca, 1990. 380p.

NESHEIM, M.C. et al. Poultry production. 12.ed. Philadelphia: Lea \& Febiger, 1979. 339 p.

OLIVEIRA, A.S. et al. Eficácia de diferentes métodos de destoxificação da ricina no farelo de mamona. In: CONGRESSO DA REDE BRASILEIRA DE TECNOLOGIA E PRODUÇÃO DE BIODIESEL, 2., 2006, Brasília, DF. Anais... Brasília: Rede Brasileira de Tecnologia e Produção de Biodiesel, 2006. p.1-6.
PAULINO, P.V.R. et al. Integração lavoura-pecuária: utilização do pasto e subprodutos. In: SIMPÓSIO DE PRODUÇÃO DE GADO DE CORTE, 5.; SIMPÓSIO INTERNACIONAL DE PRODUÇÃO DE GADO DE CORTE, 2006, Viçosa, MG. Anais... Viçosa: UFV, 2006. p.187-219.

ROSTAGNO, H.S. et al. Tabelas brasileiras para aves e suínos: composição de alimentos e exigências nutricionais. Viçosa: UFV, 2011. 252p.

SANTOS, P.A. Avaliação do farelo de mamona processado na alimentação de codornas japonesas. 2011. 79f. Dissertação (Mestrado em Zootecnia) - Universidade Federal Rural do Pernambuco, PE.

SILVA, D.J.; QUEIROZ, A.C. Análise de alimentos: métodos químicos e biológicos. 3.ed. Viçosa:UFV, 2002. 235p. 